


\section{About IJMA [last updated October, $\left.1^{\text {st }}, 2021\right]$}

$\checkmark$ International Journal of Medical Arts is the Official Journal of the Damietta Faculty of Medicine, AlAzhar University, Egypt

$\checkmark$ It is an International, Open Access, Double-blind, Peer-reviewed Journal

$\checkmark$ Published four times a year

$\checkmark$ The First Issue was published in July 2019

$\checkmark$ Published under the following license: Creative Commons Attribution-ShareAlike 4.0 International Public License (CC BY-SA 4.0). It had updated from the Creative Commons license [CC BY] in volume 2, Issue 4, October 2020 About IJMA

$\checkmark$ The Egyptian Knowledge Bank hosts the web site of IJMA

$\checkmark$ The Egyptian Knowledge Bank supports IJMA

$\checkmark$ IJMA follows the regulations of the International Committee of Medical Journal Editors

$\checkmark$ IJMA is indexed in the "Directory of Open Access Journals" [15 January 2021].

$\checkmark$ IJMA is indexed in J-Gate [29-6-2021]

$\checkmark$ IJMA is a member of the International Society of Managing and Technical Editors

$\checkmark$ Listed in "Index Copernicus", "Publons", "Academic resource index [ResearchBib]" "Electronics journal library", "Eurasian Scientific Journal Index", "WorldCat" Superstar Journal Database, and "Citefactor"

$\checkmark$ IJMA introduced to the search engine [BASE] through DOAJ

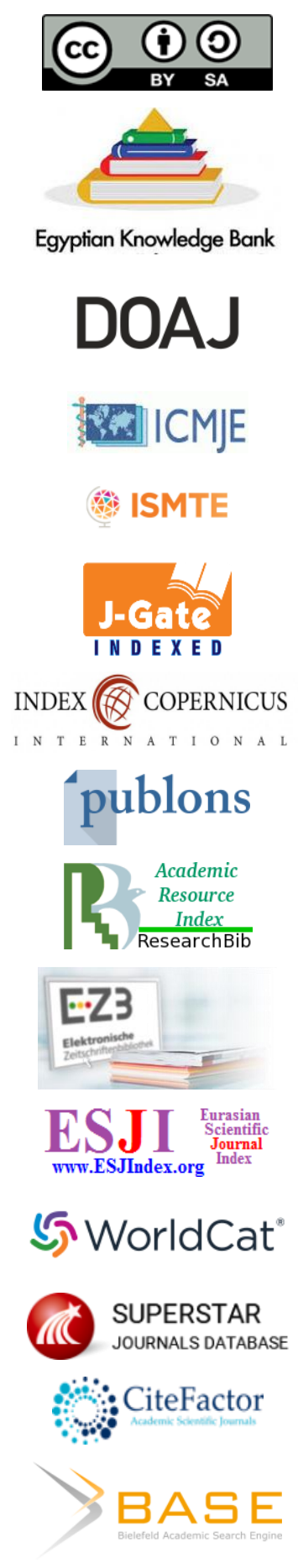




Available online at Journal Website
https://ijma.journals.ekb.eg/
Main subject [Otorhinolaryngology]

Original Article

\title{
Comparative Study between Early Tracheostomy and Extended Endotracheal Intubation in Severe Head Injury
}

\author{
Hussein Magdy Abdelkader [1], Esmail H. Ramadan [2], Ahmed M.M Elgarhy [3] \\ 1 Department of Otorhinolaryngology, Faculty of Medicine, Al-Azhar University, Assiut, Egypt. \\ ${ }^{2}$ Consultant of General Surgery, El Haram hospital, Giza, Egypt. \\ ${ }^{3}$ Department of Anaesthesia and Intensive Care Unit, Faculty of Medicine, Al-Azhar University, Egypt.
}

Corresponding author: Hussein Magdy Abdelkader

Email: hussein.magdy@yahoo.com

Submission date: June 17, 2021; Acceptance date: August 15, 2021

DOI: 10.21608/IJMA.2021.81116.1329

\begin{abstract}
Background: The optimal tracheostomy time is considered a debatable issue for patients with severe Head injury in intensive care units [ICUs], which require mechanical ventilation [MV] for long period.

The aim of the work: The current study aimed to investigate the effect of tracheostomy operation in early few days of admission on the length of mechanical ventilation [MV]. In addition, to determine outcomes and associated mortality rate.

Patients and Methods: a prospective randomized Comparative clinical study included 200 patients admitted to ICU units of Al-Azhar university hospitals and El Haram hospital who had the following criteria: severe head injury, Cerebral trauma on and Glasgow Coma Scale [GCS] score 8 or less on the fourth day viewed by brain CT scan done without given any sedation. Divided into 2 groups on the fourth day of admission each group includes 100 patients, one group submitted to early Tracheostomy [ET] [group A] and the other group submitted to extended endotracheal intubation [EEI] [Group B].
\end{abstract}

Results: There was shorter in the main period of the mechanical ventilatory support for group A than group B with statistically significant relationship $p$ value $=0.02$. Their no remarkable difference in the occurrence of Nosocomial pneumonia between group $A$ and group B. $p$ value of Nosocomial pneumonia $=0.62$.

Conclusion: In severe head injury, ET significantly decreases the mechanical ventilation time.

Keywords: Endotracheal Intubation; Tracheostomy; Complications of Tracheostomy; Severe Head Injury; Mechanical Ventilation.

This is an open-access article registered under the Creative Commons, ShareAlike 4.0 International license [CC BY-SA 4.0] [https://creativecommons.org/licenses/by-sa/4.0/legalcode.

Citation: Abdelkader HM, Ramadan EH, Elgarhy AMM. Comparative Study between Early Tracheostomy and Extended Endotracheal Intubation in Severe Head Injury. IJMA 2021; 3[4] October-December: 1772-1776. [DOI: 10.21608/IJMA.2021.81116.1329].

${ }^{*}$ Main subject and any subcategories have been classified according to the research topic 


\section{INTRODUCTION}

Traumatic brain injury [TBI] is a global health issue with a high mortality and disability rate. Intubation and invasive mechanical ventilation are frequently required in braininjured patients with altered awareness to protect the airways from aspiration and to prevent dangerous secondary insults [1]. TBI is thought to be responsible for 287.2 hospital admissions and $11.7 \%$ of all fatalities in Europe each year ${ }^{[2]}$.

A Tracheotomy is commonly done to aid management of airway of patients with severe head injury in intensive care unit [ICU] which needing sustained mechanical Ventilatory support [MVS] [3].

Tracheostomy can facilitate weaning in long-term ventilated patients, potentially shortening the duration of mechanical ventilation and intensive care unit [ICU] stay, and reducing complications from prolonged tracheal intubation, such as ventilator-associated pneumonia [VAP] and tracheal lesions ${ }^{[4]}$.

In spite of its advantages, the ideal tracheostomy time in ICU patients needing sustained endotracheal intubation is dispute. The 1989 study by the American National Association of Medical Directors of Respiratory Care found that tracheostomy operation is sufficient for mechanical Ventilatory support to last longer than 21 days, but endotracheal intubation is recommended for patients who need mechanical ventilation for 10 days or less. Some researchers commended early tracheostomy [5], while others discourage it because of doubtful benefits of tracheostomy versus endotracheal intubation ${ }^{[6]}$.

\section{THE AIM OF WORK}

The current study aimed to investigate the effect of tracheostomy operation in early few days of admission on the length of mechanical ventilation [MV]. In addition, to determine outcomes and associated mortality rate.

\section{PATIENTS AND METHODS}

This is a prospective randomized analysis conducted at Al-Azhar university hospitals and El-Haram hospital from February 2018 to February 2021. After approval of ethics committee and taken of informed written consent.

Sample size calculation was carried out using G*Power 3 software. The study was conducted on 220 patients with serious head trauma in our ICUs. Twenty of these patients were excluded because the following: 1] their families refused to participate in the study; 2] death during hospitalization; 3] improvement during the first four days of admission.

\section{Criteria for inclusion:}

- Serious head injury.

- Cerebral trauma on and Glasgow Coma Scale score 8 on the fourth day viewed by brain CT scan done without given any sedation.

On the fourth day of intensive care unit [ICU] admission if patients fit these criteria, randomly patients were separated into 2 groups: group 1 early tracheostomy $[A]$, group 2 extended endotracheal intubation $[\mathrm{B}]$.

In group $[A]$ the operation of early tracheostomy was done on $4^{\text {th }}$ or $5^{\text {th }}$ day of admission using cuffed Tracheostomy tubes of low pressure.

Socio-demographic history, Glasgow Coma Scale [GCS] score and results, specifically assessment of the period of mechanical Ventilatory support, Simplified Acute Physiologic Score [SAPS], time of stay on ICU, frequency pneumonia incidence and mortality rate were compared.

Complications related to the operation of early tracheostomy and extended endotracheal intubation [EEI] were reported clinically, but not endoscopic ones. By using $\mathrm{CDC}$ criteria, the pneumonia was diagnosed [7]

\section{Statistical analysis:}

The data were collected, coded and analyzed using IBM-SPSS 23.0 [IBM-SPSS Inc., Chicago, IL, USA]. Descriptive statistics: Means, standard deviations, medians, ranges and percentages were calculated. The test of Significance: The chi-square test was done to contrast the variation in the distribution of frequencies between two groups. For the continued variables; independent t-test analysis was carried out to contrast the methods of dichotomous data. The probability of less than 0.05 was used as cut off point for all significant tests.

\section{RESULTS}

We compare the two groups in forms of age, sex, and SAPS as shown in the table [1].

There was shorter mean period of assistance mechanical Ventilatory support of group $A$ than group $B$ with a statistically remarkable relationship $p$ value $=0.02$ [Figure 1] as shown in [Table 2]. 
There was no remarkable difference between the occurrence of Nosocomial pneumonia in group $A$ and group $B p$ value $=0.62$ [Table 3]. The mean period of pneumonia diagnosed was [5.7 \pm 1.7$]$ for group $A$, which was later than time for group B [8.2 \pm 2.44$]$.
This relationship was insignificant. After the occurrence of nosocomial pneumonia, group A needed fewer number of days with mechanical ventilation than group $B$, with statistically significant relationship $p$ value $=0.01$ [Table3]

Table [1]: Demographic characteristics and simplified acute physiological score [SAPS] among studied populations

\begin{tabular}{|c|c|c|c|c|}
\hline & Variable & $\begin{array}{c}\text { Group [A] } \\
{[n=100]}\end{array}$ & $\begin{array}{c}\text { Group [B] } \\
{[n=100]}\end{array}$ & $P$ value \\
\hline \multicolumn{2}{|c|}{ Age [years] [mean $\pm S D$ ] } & $52.9175 \pm 16.12$ & $50.9165 \pm 14.12$ & 0.54 \\
\hline \multirow[t]{2}{*}{ Sex } & Male & 60 [60.0\%] & 55 [55.0\%] & 0.34 \\
\hline & Female & $40[40.0 \%]$ & $45[45.0 \%]$ & \\
\hline \multicolumn{2}{|c|}{ SAPS [Mean $\pm S D$ ] } & $5.4 \pm 1.5$ & $6 \pm 3.8$ & 0.53 \\
\hline
\end{tabular}

SAPS, simplified acute physiological score.

Table [2]: Data about mechanical ventilation among studied populations

\begin{tabular}{|l|c|c|c|}
\hline Variable & $\begin{array}{c}\text { Group [A] } \\
{[n=100]}\end{array}$ & $\begin{array}{c}\text { Group [B] } \\
{[n=100]}\end{array}$ & $P$ value \\
\hline Number of weaning attempts & $2 \pm 0.7$ & $1.9 \pm 0.9$ & 0.68 \\
\hline Total ventilation days & $13.2 \pm 6.1$ & $16.5 \pm 7.6$ & $0.02^{*}$ \\
\hline Day of extubation or tracheostomy off & $25.2 \pm 12.4$ & $18.3 \pm 8.4$ & $0.03^{*}$ \\
\hline
\end{tabular}

* Significant difference $[p<0.05]$

Table [3]: Frequency of nosocomial pneumonia among studied populations

\begin{tabular}{|l|c|c|c|}
\hline \multicolumn{1}{|c|}{ Variable } & $\begin{array}{c}\text { Group [A] } \\
{[n=100]}\end{array}$ & $\begin{array}{c}\text { Group [B] } \\
{[n=100]}\end{array}$ & P value \\
\hline Percentage of Nosocomial pneumonia $n[\%]$ & $55[55 \%]$ & $58[58 \%]$ & 0.62 \\
\hline The day of NP was diagnosed & $5.7 \pm 1.7$ & $8.2 \pm 2.44$ & 0.94 \\
\hline The days of mechanical ventilation after pneumonia diagnosed & $6 \pm 4.3$ & $11.9 \pm 5$. & 0.01 \\
\hline
\end{tabular}

$\mathrm{NP}$, nosocomial pneumonia

Table [4]: Mortality and Outcomes among studied populations

\begin{tabular}{|c|c|c|c|}
\hline \multirow[t]{2}{*}{ Variable } & Group [A] & Group [B] & \multirow[t]{2}{*}{$P$ value } \\
\hline & {$[n=100]$} & {$[n=100]$} & \\
\hline Recovery n [\%] & 75 [75\%] & 70 [70\%] & 0.5 \\
\hline Bleeding n [\%] & $3[3 \%]$ & $5[5 \%]$ & 0.7 \\
\hline Death $\mathrm{n}[\%]$ & $22[20 \%]$ & $25[25 \%]$ & 0.5 \\
\hline
\end{tabular}

Table [5]: Causes of Death among studied populations

\begin{tabular}{|c|c|c|}
\hline \multirow[t]{2}{*}{ Variable } & Group [A] & Group [B] \\
\hline & {$[n=100]$} & {$[n=100]$} \\
\hline Intracranial hypertension & $9[9.0 \%]$ & $7[7.0 \%]$ \\
\hline Sepsis & $5[5.0 \%]$ & $8[8.0 \%]$ \\
\hline ARDS & $7[7.0 \%]$ & $5[5.0 \%]$ \\
\hline Pulmonary embolism & $1[1.0 \%]$ & $5[5.0 \%]$ \\
\hline
\end{tabular}




\section{DISCUSSION}

In severely ill TBI patients, ttracheostomy is a safer choice. A globally acknowledged tracheostomy strategy is needed to help maximize indications and outcomes ${ }^{[8]}$.

In our study, we discovered that group A had a shorter mean period of mechanical ventilation support than group $B$, with a statistically significant connection $P$ value $=0.02$. There was no significant difference in the occurrence of nosocomial pneumonia between groups $A$ and $B$, with a $P$ value of 0.62 .

Group A required fewer days of mechanical ventilation after the incidence of nosocomial pneumonia than group $B$, with a statistically significant connection $[P$ value $=$ $0.01]$. There was no significant difference in mortality rates between groups $A$ and $B$.

Robba et al. reported similar results, finding that tracheostomy is regularly performed in severe neurologically affected patients after TBI. Early tracheostomy is linked to a better neurological prognosis and shorter hospital stay, however the causality of this link is unknown ${ }^{[4]}$.

Lu et al. in a meta-analysis study comparing the results of Early Tracheostomy versus delayed tracheotomy or extended intubation in ICU patients with Severe traumatic brain injury [TBI], 8 studies found that the ET might reduce the number of days in the ICU [mean difference, -3.08; 95 percent confidence interval [Cl], $-3.75: 2.41$, the length of mechanical ventilation [MD, $-4.92 ; 95$ percent $\mathrm{Cl},-6.82$ to -3.02], and pneumonia incidence [9].

If extended endotracheal intubation is recommended for a variety of underlying causes, Kumar et al. discovered that tracheostomy in the intensive care unit [ICU] is an important and safe operation [10].

Patients with ET had marginally fewer days in the hospital [46.4 vs. 38.6 days; $P=0.048$ ] and ICU stay [34.9 vs. 26.7 days; $P=0.003$ ], according to Khalili et al. There was no significant difference in mortality rates between the two study groups $[P>0.99]$. The ET group had a decreased incidence of pneumonia [11]. Altman et al. confirmed that ET was linked to early ICU release and shorter hospital stays in their institution [12]

A retrospective study in India looked at individuals over the age of 18 who were admitted to the hospital's neurotrauma unit [NTU].

Zirpe et al. performed a percutaneous tracheostomy
[PCT] from June 2010 to November 2014. In terms of age, sex, and GCS score, there were no significant differences between the study groups $P<0.01$. The ET patients required significantly fewer days of mechanical ventilation [mean 8.1 vs. 11.7 days, $P=0.000$ ] and spent significantly less time in the hospital [mean 28.8 vs. 34.37 days, $\mathrm{P}=0.019]$; however, there was no remarkable difference in mortality rates between the early and late Tracheostomy groups $[P=0.480]^{[13]}$.

Early tracheostomy in patients with brainstem hemorrhage can shorten neurosurgical intensive care unit stay and enhance prognosis at 30 days, according to Ding et al. [14].

There was a total of 4,219 studies found and evaluated. A total of eight studies were chosen for the systematic review; with seven of them being qualified for meta-analysis. Between the early tracheostomy and late tracheostomy groups, comparative analyses were undertaken. Early tracheostomy procedures took 5.59 days [SD, 0.34 days] and late tracheostomy procedures took 11.8 days [SD, 0.81 days], respectively. When compared to late tracheostomy, early tracheostomy was linked with shorter mechanical ventilation duration [ $-4.15\{95$ percent $\mathrm{Cl},-6.30$ to -1.99$\}]$, ICU [-5.87 $\mathrm{d}\{95$ percent $\mathrm{Cl},-8.74$ to $-3.00 \mathrm{~d}\}]$ and hospital [-6.68 d $\{95$ percent $\mathrm{Cl},-8.03$ to $-5.32 \mathrm{~d}\}]$ stay lengths. Early tracheostomy was linked with a lower incidence of ventilator-related pneumonia [risk difference, 0.78; 95 percent confidence interval: 0.70-0.88].There was no statistical difference in mortality between the groups ${ }^{[14]}$.

Blot et al. discovered that the time required for hospitalisation and artificial breathing assistance was significantly longer in the early tracheostomy group [15].

\section{Conclusion:}

In spite of prior apprehension about large incidence of mortality rates in the patient group of early Tracheostomy with serious head injury on the fourth day of hospital admission is beneficial and significantly decreases the mechanical ventilation period. So decreasing the period of hospitalization and stay in intensive care unit [ICU].

\section{Financial and non-financial relationships and activities of interest}

\section{None}




\section{REFERENCES}

1. Picetti E, Pelosi P, Taccone FS, Citerio G, Mancebo J, Robba $\mathrm{C}$; on the behalf of the ESICM NIC/ARF sections. VENTILatOry strategies in patients with severe traumatic brain injury: the VENTILO Survey of the European Society of Intensive Care Medicine [ESICM]. Crit Care. 2020 Apr 17; 24[1]:158. DOI: 10.1186/s13054-020-02875-w.

2. Gravesteijn BY, Sewalt CA, Nieboer D, Menon DK, Maas A, Lecky F, Klimek M, Lingsma HF; CENTER-TBI collaborators. Tracheal intubation in traumatic brain injury: a multicentre prospective observational study. Br J Anaesth. 2020 Oct; 125 [4]:505-517. DOI: 10.1016/j.bja.2020.05.067.

3. Blot F, Similowski T, Trouillet JL, Chardon P, Korach JM, Costa MA, et al. Early tracheotomy versus prolonged endotracheal intubation in unselected severely ill ICU patients. Intensive Care Med. 2008 Oct; 34[10]:1779-87. DOI: $10.1007 / s 00134-008-1195-4$.

4. Robba C, Galimberti S, Graziano F, Wiegers EJA, Lingsma $\mathrm{HF}$, laquaniello $\mathrm{C}$, et al. Tracheostomy practice and timing in traumatic brain-injured patients: a CENTER-TBI study. Intensive Care Med. 2020 May; 46[5]:983-994. DOI: $10.1007 / \mathrm{s} 00134-020-05935-5$.

5. McCredie VA, Alali AS, Scales DC, Adhikari NK, Rubenfeld GD, Cuthbertson BH, Nathens AB. Effect of Early Versus Late Tracheostomy or Prolonged Intubation in Critically III Patients with Acute Brain Injury: A Systematic Review and MetaAnalysis. Neurocrit Care. 2017 Feb; 26[1]:14-25. DOI: 10.1007/s12028-016-0297-z.

6. Adly A, Youssef TA, El-Begermy MM, Younis HM. Timing of tracheostomy in patients with prolonged endotracheal intubation: a systematic review. Eur Arch Otorhinolaryngol. 2018; 275[3]:679-690. DOI: 10.1007/s00405-017-4838-7.

7. Freeman BD. Tracheostomy Update: When and How. Crit Care Clin. 2017 Apr; 33[2]:311-322. DOI: 10.1016/j.ccc. 2016.12.007.
8. Quiñones-Ossa GA, Durango-Espinosa YA, PadillaZambrano H, Ruiz J, Moscote LR, Galwankar S, et al. Current Status of Indications, Timing, Management, Complications, and Outcomes of Tracheostomy in Traumatic Brain Injury Patients. J Neurosci Rural Pract. 2020 Apr; 11[2]:222-229. DOI: 10.1055/s-0040-1709971.

9. Lu Q, Xie $Y$, Qi X, Li X, Yang S, Wang Y. Is Early Tracheostomy Better for Severe Traumatic Brain Injury? A Meta-Analysis. World Neurosurg. 2018 Apr; 112:e324-e330. DOI: 10.1016/j.wneu.2018.01.043.

10. Kumar P, Misra A, Anand R, Shastri BVR, Wadhawan S. Audit of the existing attitudes and practices of the medical intensivists regarding tracheostomy in the ICU's in India. Indian J. Anaesth. 2006;50(4):288-294.

11. Khalili H, Paydar S, Safari R, Arasteh P, Niakan A. Experience with Traumatic Brain Injury: Is Early Tracheostomy Associated with Better Prognosis? World Neurosurg. 2017; 103:88-93. DOI: 10.1016/j.wneu.2017. 02.060.

12. Altman KW, Ha TN, Dorai VK, Mankidy BJ, Zhu H. Tracheotomy Timing and Outcomes in the Critically III: Complexity and Opportunities for Progress. Laryngoscope. 2021 Feb; 131[2]:282-287. DOI: 10.1002/lary.28657.

13. Zirpe KG, Tambe DV, Deshmukh AM, Gurav SK. The Impact of Early Tracheostomy in Neurotrauma Patients: A Retrospective Study. Indian J Crit Care Med. 2017 Jan;21(1):6-10. doi: 10.4103/0972-5229.198309.

14. Ding WL, Xiang YS, Liao JC, Wang SY, Wang XY. Early tracheostomy is associated with better prognosis in patients with brainstem hemorrhage. J Integr Neurosci. 2020 Sep 30; 19[3]:437-442. DOI: 10.31083/j.jin.2020.03.25.

15. Blot F, Guiguet M, Antoun S, Leclercq B, Nitenberg G. Early tracheotomy in neutropenic, mechanically ventilated patients: rationale and results of a pilot study. Support Care Cancer. 1995; 3[5]:291-6. DOI: 10.1007/ BF00335304. 


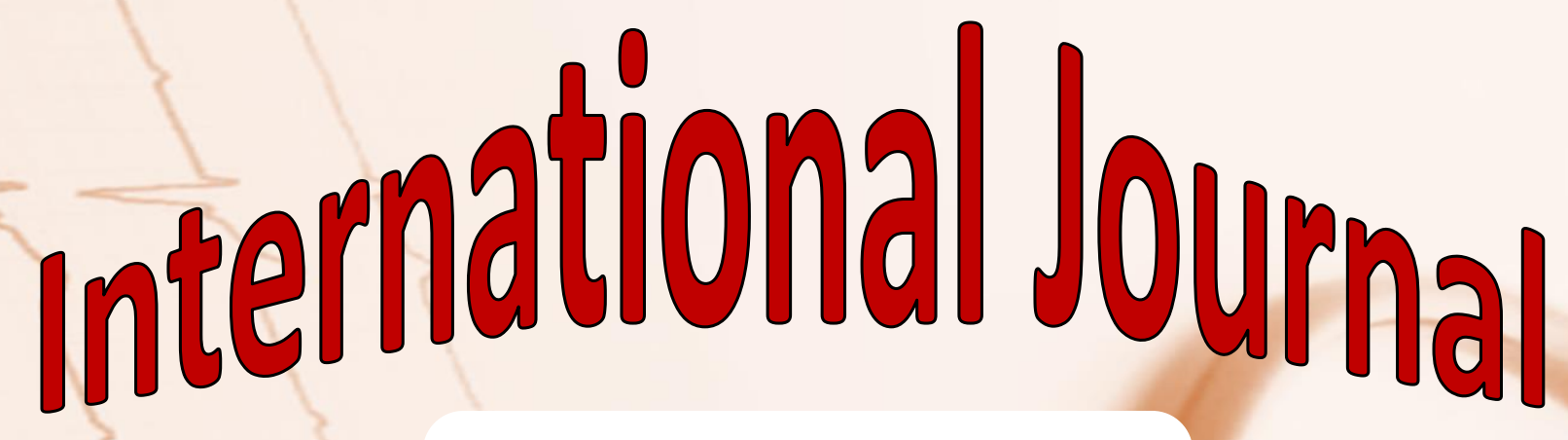

https://ijma.journals.ekb.eg/ Print ISSN: 2636-4174 Online ISSN: 2682-3780

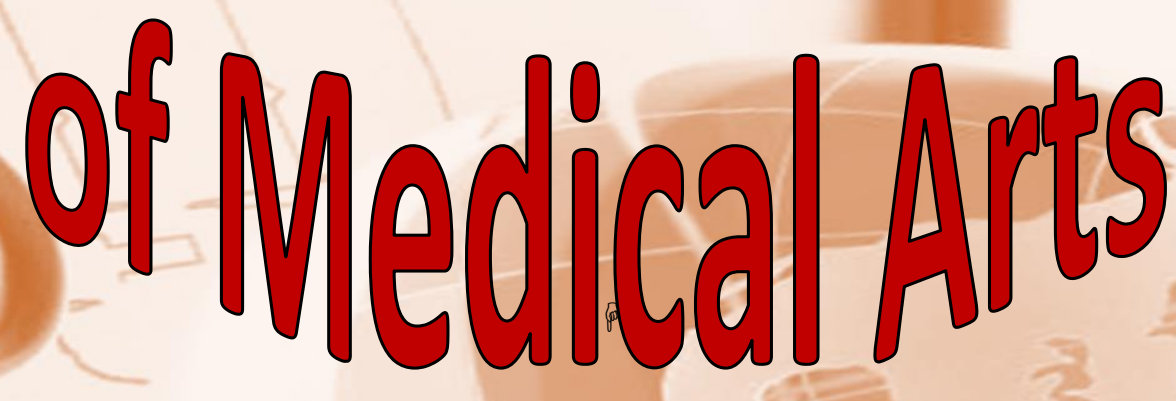

